\title{
Commentary: With left main coronary external compression, does compression relief correct stenosis?
}

\author{
Vincent R. Conti, MD
}

\author{
From the Division of Cardiovascular and Thoracic Surgery, Department of Surgery, University of Texas Medical \\ Branch, Galveston, Tex. \\ Disclosures: Author has nothing to disclose with regard to commercial support. \\ Received for publication Feb 26, 2019; accepted for publication Feb 26, 2019; available ahead of print April 2, \\ 2019. \\ Address for reprints: Vincent R. Conti, MD, Division of Cardiovascular and Thoracic Surgery, Department of Sur- \\ gery, University of Texas Medical Branch, 301 University Blvd, Galveston, TX (E-mail: vconti@utmb.edu). \\ J Thorac Cardiovasc Surg 2020;159:e203 \\ 0022-5223/\$36.00 \\ Copyright (c) 2019 by The American Association for Thoracic Surgery \\ https://doi.org/10.1016/j.jtcvs.2019.02.108
}

Steger and colleagues ${ }^{1}$ provide excellent imaging of a patient with a giant pulmonary artery aneurysm (PAA) assumed due to primary pulmonary hypertension. After the patient underwent aneurysm resection he had progressive right heart failure requiring veno-arterial extracorporeal membrane oxygenation support without survival beyond 2 weeks. The patient was also documented by imaging to have high-grade left main coronary (LMC) compression and stenosis and was symptomatic with angina for a few months before surgery, which involved only replacement of the aneurysmal pulmonary artery. It was assumed that releasing the external compression would correct the LMC stenosis and that priority had to be given to resecting the aneurysmal and dissected pulmonary artery. The authors cite Galie and colleagues, ${ }^{2}$ who reported 48 patients with LMC compression who had LMC percutaneous coronary intervention (PCI) because of angina symptoms associated with pulmonary hypertension and PAA. They also reported 3 patients who had pulmonary artery reduction plasty all with excellent results. In another report on PAA from the Mayo Clinic by Reisenauer and colleagues, ${ }^{3} 38$ patients with mean PAA diameter of $5.8 \mathrm{~cm}$ had only 1 patient with left main compression and all survived operation to repair the aneurysm. In a more recent study by Nuche and colleagues, ${ }^{4}$ among 77 patients with PAA, 7 patients had left main stenosis with 4 undergoing left main PCI. Although Steger and colleagues ${ }^{1}$ describe the deterioration and eventual death of their patient as due to right heart failure, one has to question whether the assumption that relief of the external compression from the PAA would also relieve the LMC compression and whether concomitant

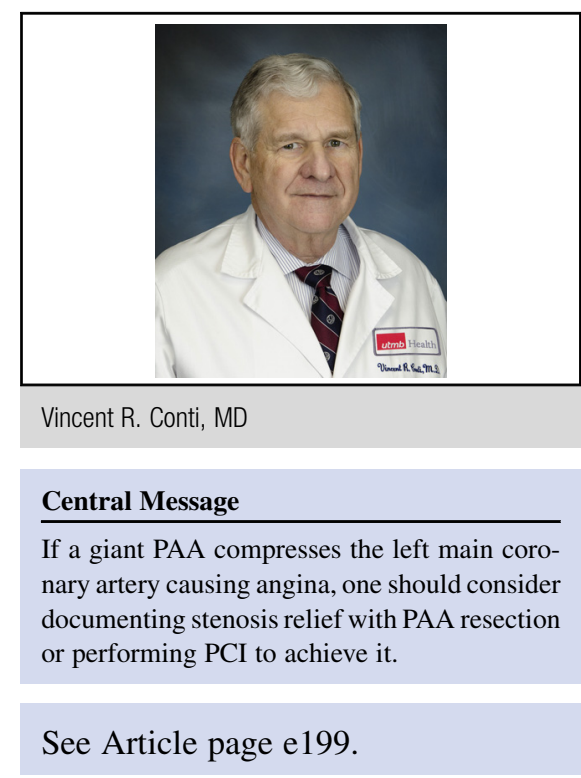

left main PCI may have improved the chances of cardiac recovery in this case. Adding coronary angiogram after PAA repair and documenting LMC stenosis relief or proceeding to left main PCI if significant stenosis persisted, even with the patient receiving veno-arterial extracorporeal membrane oxygenation support for right heart failure would have ensured that all interventions to achieve recovery had been done.

\section{References}

1. Steger A, Deutsch M-A, Lange R, Ibrahim T. Symptomatic chronically dissected giant pulmonary artery in a patient with pulmonary arterial hypertension. J Thorac Cardiovasc Surg. 2020;159:e199-201.

2. Galie N, Saia F, Palazzini M, Manes A, Russo V, Bacchi Reggiani ML, et al. Lef main coronary artery compression in patients with pulmonary arterial hypertension and angina. J Am Coll Cardiol. 2017;69:2808-17.

3. Reisenauer JS, Said SM, Schaff HV, Connolly HM, Maleszewski JJ, Dearani JA. Outcome of surgical repair of pulmonary artery aneurysms: a single-center experience with 38 patients. Ann Thorac Surg. 2017;104:1605-10.

4. Nuche J, Montero Cabezas JM, Jimenez Lopez-Guarch C, Velazquez Martin M, Alonso Charterina S, Revilla Ostolaza Y, et al. Frequency, predictors, and prognostic impact of pulmonary artery aneurysms in patients with pulmonary arterial hypertension. Am J Cardiol. 2019;123:474-81. 